\title{
Јом \\ Step by step towards citizen science - deconstructing youth participation in BioBlitzes
}

\author{
Julia Lorke, Heidi L. Ballard, Annie E. Miller, Rebecca D. Swanson, \\ Sasha Pratt-Taweh, Jessie N. Jennewein, Lila Higgins, \\ Rebecca F. Johnson, Alison N. Young, Maryam Ghadiri Khanaposhtani \\ and Lucy D. Robinson
}

\begin{abstract}
BioBlitzes, typically one-day citizen science (CS) events, provide opportunities for the public to participate in data collection for research and conservation, potentially promoting deeper engagement with science. We observed 81 youth at 15 BioBlitzes in the U.S. and U.K., identifying five steps participants use to create a biological record (Exploring, Observing, Identifying, Documenting and Recording). We found 67 youth engaged in at least one of the steps, but seldom in all, with rare participation in Recording which is crucial for contributing data to CS. These findings suggest BioBlitzes should reduce barriers to Recording for youth to increase engagement with science.
\end{abstract}

Keywords

Citizen science; Public engagement with science and technology; Science education

DOI

https://doi.org/10.22323/2.20040203

Submitted: 7th November 2020

Accepted: 2nd March 2021

Published: 14th June 2021

Context and objectives

In recent years, opportunities for participation in Citizen Science (CS) have increased, as have expectations of its potential for public engagement, education and scientific research. The majority of the many attempts to define CS [e.g. Haklay et al., 2020; Shirk et al., 2012; Bonney et al., 2009] seem to agree that its "common, shared goal is to collect and analyze information that is scientifically valuable" and that this "distinguishes citizen science from areas such as experiential learning or environmental education" [Hecker et al., 2018, p. 2]. Different typologies of CS projects [e.g. Shirk et al., 2012; Haklay, 2013] are commonly based on the range and extent of participants' contribution to the scientific process, for example, to determine whether a CS project is best described as "contributory", "collaborative" or "co-created" [Shirk et al., 2012]. For this study, we move beyond the assumed opportunities for participation in the scientific process to focus on actual participation in CS programs, investigating what activities youth (5-19 years old) 
actually engage in when participating in BioBlitzes. BioBlitzes fall into the category of "contributory" CS because they are typically scientist-driven [Shirk et al., 2012], with the scientific aim of collecting biodiversity data with the help of non-experts that can be used for scientific research, monitoring or land management.

Our study explores how youth participate in BioBlitzes. We do not evaluate the success of the events as a whole in their contribution to science, instead, we focus solely on youth participation in the scientific process inherent within BioBlitz events. Through our lens, we are able to analyze youth's experiences of participating in a BioBlitz as a scientific endeavour, as opposed to similar environmental education or public engagement activities (i.e. nature walks or pond dipping activities) that lack this scientific purpose [Hecker et al., 2018].

We operate under the premise that participating in the data submission step of a CS project, known as Recording in biological monitoring, is a crucial aspect of youth participation in BioBlitzes because a) only recorded data can be used for scientific research or monitoring purposes, and b) interaction with and ownership of scientific data they have gathered has proven important for the development of agency within youth, at least in ongoing CS activities [Harris et al., 2020]. Understanding participation is salient for event design and studying the outcomes of short-term CS events. Our research will address assumptions that taking part in a BioBlitz automatically equates to contributing data to the scientific purpose, proposing a more fine-grained framework to describe participation in CS.

\section{Biological recording and citizen science}

One aim of the Convention of Biological Diversity [United Nations, 1992] was to address threats to biodiversity through scientific assessment, such as monitoring climate change impacts on biodiversity. Therefore, the practice of biological recording, established in the 17th century [Pocock et al., 2015], stays relevant today. But, what constitutes a biological record?

According to Pocock et al. [2015], a "biological record is, at its simplest, a record of a species in a particular place at a particular time by a named person." It consists of answers to four questions [Isaac and Pocock, 2015]: What? (the identity of the species observed), Where? (the spatial location it was observed), When? (the date, or date range, it was observed) and Who? (the person who made the record). The generated records are ideally shared with networks such as the Global Biodiversity Information Facility (GBIF) to make them accessible for further research.

While biological recording has largely been undertaken by non-professionals long before the term 'citizen science' was coined, the CS approach broadens the audience for biological recording by involving non-expert members of the public. The paradigm change in science communication from deficit and dialogue to participation [Lewenstein and Brossard, 2009] altered the mission of many science education stakeholders including Natural History Museums (NHMs). Building on their experience of collaboration across amateur-expert communities and aligned with their dual mission of education and scientific research, it is not surprising that NHMs engage in CS through multiple approaches, including capacity building (e.g. in form of guides and training courses) as well as developing and running 
CS programs. Ballard et al. [2017] demonstrated that NHM-led CS programs can contribute to conservation research, management, education and policy.

\section{BioBlitzes}

While specific definitions vary, BioBlitzes can be described as biodiversity experts and members of the public working together to generate a biodiversity inventory in one particular location over a short time frame (usually 2-24 h) [Ballard et al., 2017]. For the shorter version of BioBlitzes, the term mini-BioBlitz has been introduced [DITOs Consortium, 2019]; this format better describes the NHM-led BioBlitzes observed in this study (see Supplementary Material A for more information on BioBlitzes in general and in this study). Several studies have investigated the potential of BioBlitzes for public engagement and education. Roger and Klistorner [2016] highlight that participants value the opportunity to interact and learn from scientists, and experts enjoyed interacting with members of the public. Leong and Kyle [2014] showed that participants' motivations included contributing to society and conservation, making life better for the coming generation, and learning about different species. An evaluation of BioBlitzes in the U.K. showed that while adults enjoyed learning opportunities and interaction with experts, children preferred "practical activities, particularly those that involve direct contact with wildlife such as pond dipping and bug hunting" [Postles and Bartlett, 2018, p. 371]. The evaluation of the 2016 National Park BioBlitzes [Hartry et al., 2017] reports increases in students' comfort in being in nature, appreciation for biodiversity, and in environmental advocacy. Behavioral engagement patterns were studied using observational data, demonstrating that participants were most actively engaged when participating in science practices, and mostly passive during instructions and while walking; but never disruptive. While the qualitative categories in Hartry et al. [2017] provide insights into participants' engagement levels, they remain vague regarding the specific scientific practices in which participants took part. So, despite this evidence of engagement and education outcomes from BioBlitzes, we continue to lack an understanding of what participants actually do during the events. Are they taking up the opportunity to contribute data to science?

\section{Participation in Citizen Science}

This logic model [Shirk et al., 2012, p. 8] shows how any potential outcomes of CS are linked to the provided activities (input) and the participants' experience (output) (Figure 1). The similar model proposed by the WTimpact ${ }^{1}$ project [Bruckermann et al., 2020], further emphasizes the difference between opportunities for participation and actual participation. In both models, participation is directly linked to the outcomes of the CS project.

The affordances and constraints of CS projects vary according to subject area and project design, influencing the degree to which participants can contribute to the scientific goals. It is important to understand what participation in CS means in the specific context of any given program in order to study it effectively. What steps or tasks need to be undertaken to contribute to the scientific goals? In co-created CS projects "at least some of the public participants are actively involved in most or all

\footnotetext{
1https://www.wtimpact.de/.
} 


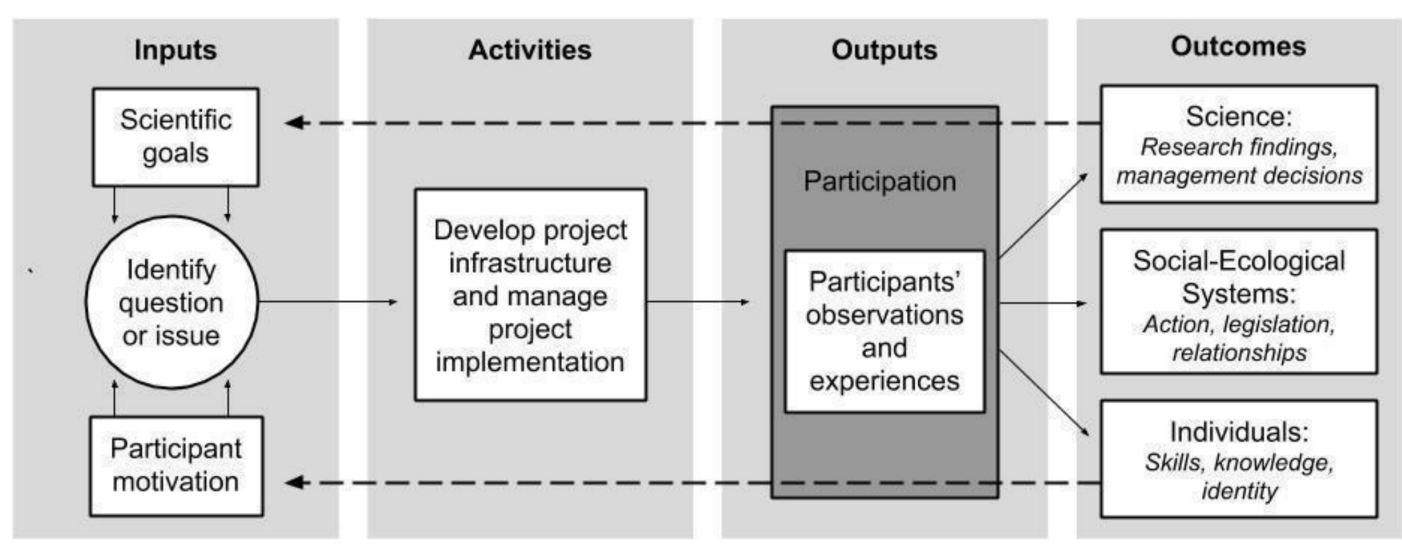

Figure 1. CS logic model (adapted from Shirk et al. [2012]).

aspects of the research process" [Shirk et al., 2012, p. 6], yet contributory CS projects are more common, with participation being mostly limited to "contributing data". Even within the same project type, the range of opportunities available to participants can vary significantly, because they are defined by the scientific goals of the CS project.

To describe the actual participation within or across CS projects, a more fine-grained perspective is needed. Some studies explored engagement in CS, for example, Phillips et al. [2019] proposed degrees of engagement in science from the participants perspective and Golumbic, Baram-Tsabari and Fishbain [2020] identified different engagement styles in participants in an ongoing CS project. In comparison, online CS projects often can track actual participation via log files and, therefore, can easily describe and categorise participation profiles [Herodotou et al., 2020]. For CS projects using kits or surveys that participants need to register for, the registration versus data submission rate can provide some insights into the data submission behaviour of the participants (according to West, Pateman and Dyke [2016], submission rates range from 10\% to 50\%). However, for more free-form, event-based CS activities, we lack data on patterns in participation; we address this knowledge gap in this study specifically around youth participation in BioBlitzes. The aims of this research were to investigate: 1) what types of participation youth actually engage in at BioBlitzes, 2) to what extent youth themselves participate in contributing data to science during the events, and 3) what patterns of participation by youth in BioBlitzes can be identified.

We observed 15 BioBlitzes led by The Natural History Museum in London, the California Academy of Sciences (San Francisco) and the Natural History Museum of Los Angeles County, with each museum (NHM) organising 4-7 events (for further information on the BioBlitzes, see Supplementary material A and for a more detailed version of the methods section, see Supplementary material B). We used ethnographic field observations [Emerson, Fretz and Shaw, 1995] to capture participation data for 81 youth. The sampling method combined random purposeful and stratified purposeful sampling [Creswell, 2014]. All demographic 
Table 1. Approximate age and presumed gender of the 81 focal youth (31 NHM London, 28 NHM Los Angeles County, 22 California Academy of Sciences) observed.

\begin{tabular}{|l|c|c|c|c|}
\hline Gender & $\begin{array}{c}5-10 \text { years } \\
\text { (elementary } \\
\text { school-age) }\end{array}$ & $\begin{array}{c}11-15 \text { years } \\
\text { (middle } \\
\text { school-age) }\end{array}$ & $\begin{array}{c}15-19 \text { years } \\
\text { (high } \\
\text { school-age) }\end{array}$ & Total \\
\hline Female & 20 & 11 & 9 & 40 \\
Male & 23 & 9 & 8 & 40 \\
Unknown & 1 & 0 & 0 & 1 \\
\hline Total & 44 & 20 & 17 & 81 \\
\hline
\end{tabular}

information (Table 1) are suppositions and were unconfirmed, as data were observational only, per ethics approval.

Our aim was to gather a variety of youth's BioBlitz experiences to get a broad picture of what youth do when attending BioBlitzes. We opted for focal sampling: observing and documenting all occurrences of behaviors of interest for a particular individual during the entire sampling period [Pellegrini, Symons and Hoch, 2004]. To increase the number of focal youth that could be observed per event, we predetermined the duration of the observation interval. Taking into account how long the average CS data collection task would last and allowing time for youth to orient themselves within the setting and activity, we set the observation duration to 20 minutes. We are aware that in any one youth's participation, our study may have missed instances of activity that may have happened outside the observation interval. This was an unavoidable limitation, unless we had narrowed the number and range of youth observed in order to follow focal youth for the whole duration of the event. Researchers primarily took the approach of "observer as participant" [Creswell, 2014]. Our protocol ensured that methods were aligned across different settings and observers [Emerson, Fretz and Shaw, 1995].

\section{Data analysis}

To analyze the ethnographic fieldnotes, we adapted Creswell's steps of Data Analysis for Qualitative Research [2014]. We identified key action/interaction episodes in which youth engaged in CS-related activities. For each key action/interaction episode, we wrote a memo containing a claim about youth participation, a description of the type of participation observed and excerpts from field notes as evidence to support the claim. At the start of the process, researchers went through a calibration phase, discussing and aligning the analytic approach in peer-review, before progressing with data analysis. The memo-writing process for each focal youth was iterative and involved two researchers per memo. Building on Pocock et al.'s [2015] components of a biological record, we identified five ways youth could potentially contribute to a BioBlitz's scientific goals, and therefore developed a priori codes for these, as follows:

Exploring - exploring and actively searching the habitat to discover organisms, potentially involving tools such as binoculars or nets.

Observing — observing organisms in nature, using one's senses to find and study organisms 
Identifying organisms — putting a name to the organism (e.g. taxon or species) that was observed

Documenting - documenting the observations by generating evidence of the observation, such as a photograph or writing on a data sheet

Recording — making the documented observation available for biodiversity monitoring or research purposes, ideally providing the Who, When, Where and What aspects of a biological record [Isaac and Pocock, 2015]

We consider the final two closely-related types of participation separately (Documenting and Recording), as not everything that is documented is necessarily shared for research purposes, and it is this onward sharing of data that distinguishes CS from other forms of engagement, and the external accountability in Recording may have implications for the development of youth agency [Harris et al., 2020].

More detailed and nuanced descriptions of the above types of participation with examples, are provided in the results section, alongside additional types of participation observed. We used these types of participation for thematic coding [Saldaña, 2009] of the memos to enable a participation type frequency analysis. Two researchers coded a sample ( $4 \%$ of the memos) including memos from each museum independently and achieved a substantial agreement $(92 \%$ agreement, Cohen's $\kappa=0.73)$. The coders discussed disagreements and settled on coding-decisions for these cases [Creswell, 2014; Saldaña, 2009]. The coders then split up the remaining memos between them and coded them independently.

Based on the observed participation types, patterns were identified to propose participation profiles. Detailed descriptions and frequency of occurrence of each profile can be found in the results section.

Results

We observed 67 of the 81 focal youth (FY) participating in at least one of the anticipated CS-relevant types of participation. Table 2 provides a brief overview of the five types of participation and the number of youth that were observed participating in each during the 20-minute observation period. For the remaining 14 focal youth, observed participation could not be categorised as CS-relevant (e.g. puppet theatre show or lecture-style presentation) and therefore, were not further analyzed.

Our coding approach allowed us to capture multiple ways a young person participated in a 20-minute observation period. The types of BioBlitz participation are not mutually exclusive even within one observation period. Therefore, the numeric statements in our results report the number of youth we observed undertaking each type of participation, to communicate the relative predominance of participation types in our data.

To characterize the participation of the 67 youth who engaged in any of the a priori defined types of participation, we provide a detailed description of the types of participation, examples from the fieldnotes, and how frequently we observed youth engaging in each of the steps. 
Table 2. Number of youth $(N=81)$ observed participating in each type of participation. Youth could participate in one, all five or any combination.

\begin{tabular}{|l|c|}
\hline Type of participation & $\begin{array}{c}\text { Number of focal youth } \\
\text { observed participating }\end{array}$ \\
\hline Exploring & 48 \\
Observing & 57 \\
Identifying & 45 \\
Documenting & 28 \\
Recording & 12 \\
Not CS-relevant & 14 \\
\hline
\end{tabular}

\section{Exploring}

Exploring included searching for wildlife, interacting with nature (e.g. turning over rocks, looking under leaves), and generally exploring the habitat. Exploring could be done with or without the use of tools (e.g. sweep nets, beating sheets, or sticks). For example, Ben, ${ }^{2}$ an elementary school-age boy in L.A., participated in Exploring when he used his hands and a spoon to reveal crabs and other tidepool organisms.

Another example, from a beetle walk, shows that for this type of participation, the effort of searching for wildlife was enough to be coded as such; it was not necessary to find organisms.

"Nina walks back towards the logs with her friend, to look underneath another log. They [...] continue turning over another 2 or 3 logs in turn, checking underneath them and putting them back down." (Female, middle school-age, London Hyde Park BioBlitz)

We observed 48 youth participating in Exploring with no major difference in participation based on gender. Of the younger groups, $68 \%$ and $70 \%$ (elementary and middle school-age respectively) were observed taking part in Exploring, while only $23 \%$ of high school-age youth were observed doing so. While Exploring was one of the most common types of participation for the two younger age groups, it was the least common type for older youth.

\section{Observing}

The process of Observing involved the youth using their senses to find, notice, or watch organisms. We observed this type of participation taking place in many different ways, with or without the use of tools (e.g. magnifying glasses, bat detectors), using different senses (e.g. touching wildlife, listening to bird calls, smelling herbs).

In one example of Observing, Layla, a middle school-age girl at an L.A. BioBlitz, looked at plants in detail and at times crouched down to pick up snails and look at them more closely.

\footnotetext{
${ }^{2}$ All names are pseudonyms.
} 
A second example demonstrates that Observing could use senses aside from sight and touch.

"Rob [adult participant] asks the group if they just heard that bird. Alex responds, "to me it sounds more like a rattle, like a high-pitched beat boxing'." (Male, high school-age, SF Lee Hill BioBlitz)

Out of 81 total youth, 57 (70\%) took part in Observing, making it the most prevalent type of participation. Age and gender did not seem to affect youth engagement in Observing.

\section{Identifying organisms}

We found a wide variety of ways that youth were involved in the identification process (Table 3). Throughout the observation intervals, youth often drew on more than one resource, and we found interesting patterns in these subcategories of Identifying.

Table 3. Variety of ways we observed youth participating in Identifying (finding out what type of organism they have found).

\begin{tabular}{|l|c|}
\hline Manner of participation in Identifying & Number of focal youth \\
\hline Using a knowledgeable person as a resource & 33 \\
$\quad$ Being told an ID & 25 \\
Being supported in identifying & 17 \\
Identifying based on prior knowledge & 16 \\
Using an ID guide or spotter sheet & 12 \\
Using iNaturalist to get an ID suggestion & 9 \\
Participating in a learning activity to develop identification skills & 3 \\
\hline Identifying organisms (total) & 45 \\
\hline
\end{tabular}

The predominant way youth identified organisms was by using a knowledgeable person at the event as a resource (33 FY). This included parents, peers, or other participants but often were scientists, volunteers, or educators who facilitated the activities. Those more knowledgeable people either identified the organism for the youth (25 FY), engaged them in identifying it themselves through conversation about characteristics, or supported them in using tools such as ID guides or iNaturalist app (see the example of Henry below). As examples of the former, a facilitator announced, "It's a brittle star." or a facilitator identified the find of a youth by saying "Oh! You found a millipede!".

Some participants identified organisms by using their prior knowledge (16 FY, only elementary and middle school-age). However, this mostly led to coarse-grained identifications, e.g. spider, ladybird, woodlouse.

"Facilitator: 'Do you know that one?' Vanessa says 'stinging nettle', correctly identifying the plant [...], points and says 'Bumblebee!', as one flits in front of them. The facilitator agrees that it is." (Female, elementary-school age, London Tring BioBlitz) 
Identification tools, such as identification guides or "spotter sheets" (worksheets with images of species and tick boxes to indicate a species was found), were used by participants to find out what organism they had found (12 FY). Some youth were able to use these identification tools on their own, but often needed some support. The following quote illustrates how a young person identified his find by using an ID guide and received support from a facilitator:

\section{"Henry points at a picture on the guide 'I think it's this.' Facilitator: 'Does it swim on its back?' Henry looks closely at the animal in the tray: 'No.' Facilitator: 'Then look again.' Facilitator: 'When you've got a larva like this, you count the bits of the tail. Which ones have three?' Henry points at three pictures. Facilitator: 'Only these three, so what do you think it is?' Henry: 'Damselfly."' (Male, middle school-age, London Hyde Park BioBlitz)}

Alternatively, having access to iNaturalist allowed participants to use its machine-learning feature to get suggestions to support them in the identification process $(9 \mathrm{FY})$.

\footnotetext{
“Silje: 'Whoa!' Silje's dad: 'Wow, that's a giant roly-poly.' The two take a picture, look at the iNat suggestions together, discussing the various options of what it could be. They settle on a pillbug" (Female, elementary school-age, SF Silicon BioBlitz)
}

Three focal youth engaged in learning activities to develop identification skills, like sorting specimens based on certain anatomical characteristics, a precursor to identifying organisms in the field.

While 30 focal youth actively engaged with the process of identification (e.g. using ID guides or iNaturalist on their own, being supported by a knowledgeable person through dialogic conversation, using the identification tools available), 15 focal youth were only told the identification of an organism and/or identified it themselves based on their prior knowledge.

The results did not show major gender- or age-related differences.

\section{Documenting}

Youth Documenting included any form of creating a written or digital record of the observation, including writing down what organism was found, drawing or taking a picture of the organism. This step did not require the document to be shared with anyone but had the potential of being shared and used for monitoring or research.

BioBlitzes that used iNaturalist as the only recording option encouraged participants to take photographs of their findings. To distinguish between Documenting and Recording, cases in which we only saw youth generate the artifact, providing evidence for an observation, but not the act of making it accessible for data analysis were considered to be "Documenting".

In BioBlitzes that did not use iNaturalist, the equivalent were instances of youth filling out "spotter" sheets or data sheets, drawing in notebooks or similar 
activities, but without evidence of them handing in these documents to scientists or other facilitators at the event. These "analog" forms of data have been the backbone of citizen science and amateur naturalist documentation for decades but require rigorous quality assurance if they get submitted (see Recording below).

For example, during a London BioBlitz an elementary school-age girl noted down information about her observations, prompted by her mother handing her the data sheet: "Bee" (under what did you see), "1" (under how many did you see) and "Hedge" (under where did you see it)". During BioBlitzes that used iNaturalist, youth were observed using smartphones or cameras to take pictures of wildlife:

"The facilitator pointed out a spider. Mike took out the camera to get closer. He took the picture." (Male, elementary school-age, L.A. DD BioBlitz)

We observed 28 youth Documenting observations. Age and gender seemed not to affect participation in Documenting.

\section{Recording}

Each BioBlitz offered one of two ways to participate in Recording: a) submitting data to iNaturalist or b) handing in documented observations in written form to a facilitator at the event. Both of those actions result in data points being made available for scientific analysis by the NHM or local land manager, or to be shared with biodiversity databases.

In some cases, participation in Recording was clear, as when youth generated a biological record by uploading data to iNaturalist:

\footnotetext{
"Nia is on an iPhone alone, taking a picture of a tree and uploading it. She scrolls through the options for identifications and chooses one [...] Nia takes a picture of the moss and uploads it to iNaturalist. She asks why iNaturalist thinks it's a tortoise? Becky says, 'Do you think it's because that's what the back of a tortoise looks like?' Nia: 'I guess so.' Ally: 'You can just type in moss.' Nia does so." (Female, elementary school-age, SF Silicon BioBlitz)
}

Further, we observed one young man (high school-age, L.A. BioBlitz) recording his own findings using iNaturalist and then helping others, "You can ID or you can just take the picture if you're not sure and someone can help you. [... ] You can still upload even if you don't know."

Other cases of participation in Recording were very brief and less obvious moments. We observed the young person using the iNaturalist app to take a picture of an organism and upload it; for example, at a BioBlitz in San Francisco, "Nathan takes a picture of the slug [...]. He makes an iNat observation and then almost immediately starts walking ahead", and "Kris uploads a picture of a poppy then walks ahead". These youth did not engage any further with the iNaturalist app (e.g. using the machine-learning feature). Nevertheless, these were considered Recording activities. 
Instead of iNaturalist, some events provided generic recording sheets asking for species name, location, and number of specimens found; the EarthwormWatch ${ }^{3}$ activity in London BioBlitzes asked for additional information on their recording sheet (e.g. about the soil characteristics at the survey site). We categorized this as Recording in those cases when youth filled in any provided recording sheet and handed it to a facilitator at the event, as in this example:

\begin{abstract}
"Natalie: 'It's a leech' and draws a tick next to the picture of the leech on the sheet [...] Natalie gives this worksheet to the activity leader before she leaves." (Female, middle school-age. London Tring BioBlitz)
\end{abstract}

In total, we found 12 focal youth that participated in Recording. There seems to be no correlation between participating in Recording and gender. These youth were spread across all three age groups: three elementary school-age $(7 \%$ of this age group), three middle school-age (15\%) and six high school-age (35\%). So, while older youth were more likely to engage in recording, even elementary school-age youth engaged in this type of participation.

\title{
Other types of participation
}

In addition to the a priori defined types of participation that derived directly from the data collection process of BioBlitzes, we observed youth taking part in other ways. Youth were observed leading and helping others, sharing their science knowledge, skills and findings. At times, youth participated in a more passive way (e.g. when listening to activity leaders). Some youth showed stewardship for wildlife and the habitat, for example, when emptying collection pots to release insects, to make sure organisms they discovered were put back where they were found, or asking others to behave in these ways. These are notable ways youth participated in BioBlitzes that were not directly linked to the contributory citizen science tasks at hand, but are often education goals of BioBlitz leaders.

\section{Identifying participation patterns}

We found that most youth participated in multiple, but not all steps. Rather than examining every possible combination of the five steps, we clustered particular combinations of participation types. We separated Exploring, Observing and Identifying as activities that do not produce any kind of artifact, whereas Documenting and Recording do, and therefore investigated the following combinations (Table 4).

The clusters of youth who participated in all five steps of the data collection process (3 FY), or participated in Recording plus any other combination of the other types (9 FY), we have labeled the "Citizen Science" profile. They all generated a biological record that can be used for monitoring or research purposes and contributed to science as intended in BioBlitzes as contributory CS programs [Shirk et al., 2012] by collecting information that is "scientifically valuable" [Hecker et al., 2018]. High school-aged youth more often fall into the Citizen Science profile.

\footnotetext{
${ }^{3}$ https:/ / www.nhm.ac.uk/take-part/citizen-science/earthworm-watch.html.
} 
Table 4. Number of FY, total and by age group, observed participating in four clusters of participation.

\begin{tabular}{|c|c|c|c|c|c|}
\hline $\begin{array}{l}\text { Participation } \\
\text { profile }\end{array}$ & $\begin{array}{l}\text { Participation } \\
\text { cluster }\end{array}$ & $\begin{array}{l}\text { 5-10 years } \\
\text { (elementary } \\
\text { school-age) }\end{array}$ & $\begin{array}{l}\text { 11-15 years } \\
\text { (middle } \\
\text { school-age) }\end{array}$ & $\begin{array}{c}16-19 \text { years } \\
\text { (high } \\
\text { school-age) }\end{array}$ & $\begin{array}{l}\text { Number of } \\
\text { focal youth }\end{array}$ \\
\hline $\begin{array}{l}\text { Environmental } \\
\text { Education }\end{array}$ & $\begin{array}{l}\text { Exploring, } \\
\text { Observing, } \\
\text { and/or } \\
\text { Identifying }\end{array}$ & $19(53 \%)$ & $11(31 \%)$ & $6(17 \%)$ & 36 \\
\hline $\begin{array}{l}\text { Natural } \\
\text { History }\end{array}$ & $\begin{array}{l}\text { Documenting } \\
\text { only or } \\
\text { Documenting } \\
\text { and Exploring, } \\
\text { Observing, } \\
\text { and/or } \\
\text { Identifying }\end{array}$ & $13(68 \%)$ & $4(21 \%)$ & $2(11 \%)$ & 19 \\
\hline Citizen Science & $\begin{array}{l}\text { Recording } \\
\text { only or } \\
\text { Recording plus } \\
\text { any other type }\end{array}$ & $2(22 \%)$ & $2(22 \%)$ & $5(56 \%)$ & 9 \\
\hline Citizen Science & $\begin{array}{l}\text { All } 5 \text { types of } \\
\text { participation }\end{array}$ & $1(33 \%)$ & $1(33 \%)$ & $1(33 \%)$ & 3 \\
\hline
\end{tabular}

We labeled the "Natural History" profile (19 FY) as participation that led to some kind of evidence for observations made, yet without the evidence being shared, meaning any combination of types of participations that included Documenting but not Recording (Table 4). The focus here is on the study of natural history: youth engaging in Exploring, Observing or Identifying, while going one step further by keeping track of their findings (Documenting) and producing evidence of their observation, without sharing it with the broader community. This focus on natural history can be distinguished from "naturalists", who historically and currently record and submit their data to organized biological recording schemes [Miller-Rushing, Primack and Bonney, 2012; Tewksbury et al., 2014].

We labeled the "Environmental Education" profile (36 FY) to describe youth that engaged in Exploring, Observing and/or Identifying, or any combination of these types of participation, without Documenting or Recording (Table 4). Participation in this category can be found in a wide variety of environmental education and public engagement events such as nature walks, pond dipping or tidepooling activities that are not citizen science as data are not collected for monitoring or research purposes.

Our findings indicate that most BioBlitzes successfully engaged youth in at least some steps necessary to generate biological records. Of the 81 observed youth, 67 participated in one or more steps towards generating a biological record. However, youth participation in Exploring (48 FY), Observing (57) and Identifying organisms (45) was much more common than participation in Documenting (28) and Recording (12).

Exploring was the most common way younger children (ages 5-15) participated, and the least common for older youth (ages 16-19). This reflects Sobel's [1995] 
Developmental Stages of Place-Based Education, positing that children aged 8-11 are in the stage of needing to explore their place to get to know it well. Observing is the most common type of participation across all age groups, likely because observing an organism is the foundation for being able to Identify, Document and Record; close observations of an organism provide the necessary information for the Who, When, What and Where of a biological record [Isaac and Pocock, 2015].

Our findings regarding youth participation in Identifying and Documenting revealed important lessons about the design of BioBlitzes. Interestingly, we found some nuance in the engagement of youth, and the tools and resources youth used for this task. Our observational data reflects the presence of both traditional teaching approaches in which expert knowledge is communicated as facts (e.g. facilitator telling youth the name of an organism) and more inquiry-based, active-learning approaches in which youth are positioned to use tools to find out for themselves [Gormally et al., 2009]. Youth participation in Documenting varied based on the structure of different BioBlitzes regarding tools available and the support for their use, e.g. camera phones or digital cameras as compared to paper datasheets. Participation in Documenting was observed less frequently than the previous three steps. Since the need to Document the organism precedes Recording, this may help to clarify why few youth participated in Recording, suggesting that BioBlitz organizers should provide multiple ways to document organisms and provide an abundance of access to tools and training to increase participation in this step, and therefore the subsequent step of Recording.

While our study revealed the many ways that youth participate in the steps towards creating biological records at BioBlitzes, we found they rarely participated in all steps, and Recording was particularly rare (12), meaning very few youth actually submitted data to the CS project. This is in contrast to the assumption that most participants at CS events contribute data to the scientific goal of BioBlitzes. But this act of data collection and sharing distinguishes BioBlitzes as citizen science programs [Robinson et al., 2013; Ballard et al., 2017; Shirk et al., 2012] from other public engagement or educational programs [Hecker et al., 2018]. Therefore, missing this step might mean participants are not as aware of the scientific purpose of the event or their role in contributing to it. The low level of youth participation in Recording poses a challenge for BioBlitz designers to better support youth participation in citizen science.

We acknowledge that whilst our focal youth may not have recorded data themselves, the BioBlitz event as a whole did contribute data that could be used for scientific research; we also acknowledge our focal youth might have handed in data sheets outside of our observation interval or later uploaded their photos to iNaturalist. This may have occurred during the "wrap-up" session that some BioBlitzes include, where participants are encouraged to upload any remaining observations. We consider it unlikely to have happened after the event, however, as a previous study shows that most young iNaturalist users submit to iNaturalist only for the day of the BioBlitz event, and further engagement with iNaturalist is rare [Aristeidou et al., 2021]. Out of the 12 focal youth that recorded, 10 used iNaturalist. Despite the very small numbers and skewed proportion of BioBlitzes in the study that exclusively used iNaturalist, this finding might indicate that recording via iNaturalist enhances the chance of youth participating in Recording, as compared to using written data sheets. However, iNaturalist is the only 
recording method for most of the observed BioBlitzes (12 out of 15) and for more than half of the observed youth (50 out of 81 FY). Also, we observed more older youth during BioBlitzes that used iNaturalist; further research is needed here.

Fourteen focal youth only engaged in non-CS-related activities, reflecting the multivariate character of BioBlitzes as an event for public engagement, learning and entertainment in addition to citizen science [Baker et al., 2014; da Silva, 2018; Roger and Klistorner, 2016]. Even if these types of participation were not related to the creation of biological records, they may be important scaffolding activities that merit further research, aiming to develop a more holistic picture of the authentic learning opportunities supplied and used [Bruckermann et al., 2020] in this case, BioBlitzes.

\section{Patterns of participation}

Our findings regarding the clusters of youth participation revealed important lessons about science and environmental learning opportunities at BioBlitzes. We identified the clusters as three distinct profiles to describe youth's participation experience: 1) "Citizen Science" profile, 2) "Natural History" profile and 3) "Environmental Education" profile (Figure 2).

The Citizen Science profile where youth participated in Recording alone or with any or all other types was the rarest (12 youth). Older youth (ages 16-19) more often fit this participation profile than younger youth (Table 4); this may be due to better access to recording tools (e.g. smartphone with iNaturalist) and greater awareness of the scientific goals of the BioBlitz, but more research is needed to examine these age-related differences.

The high proportion of youth in the Environmental Education and Natural History profiles bears highlighting and deserves further study. It might reflect the division of labor common in ecological fieldwork, where the person collecting samples or observations may not be the one to record them, or recording equipment must be shared. This may be especially true in family groups where adults do some

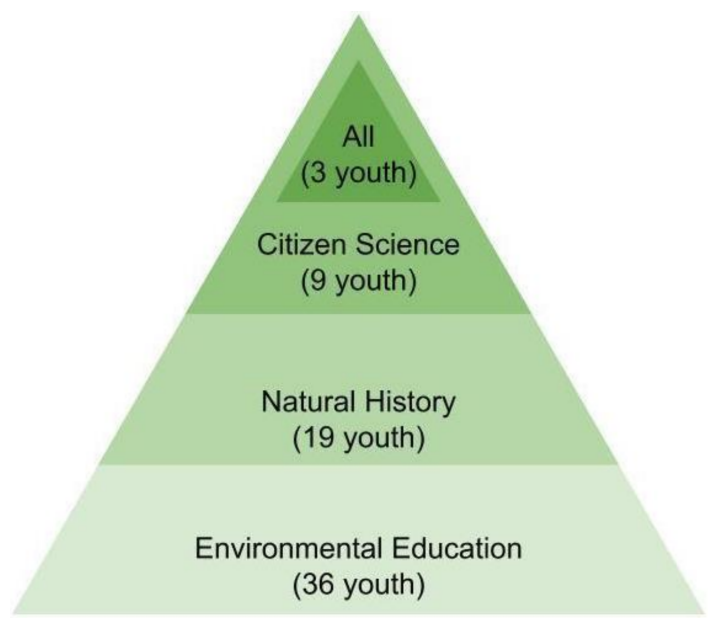

Figure 2. Participation profiles and number of youth observed matching each profile. 
activities on behalf of young children. However, this division of labor and/or lack of access to tools could indicate equity challenges, and may inadvertently present barriers to participation in the entire scientific process for youth, potentially removing valuable learning opportunities.

By examining youth participation in BioBlitzes using these profiles, we see that youth experiencing the Environmental Education or the Natural History profiles can still be seen as engaging in valuable environmental education activities, in the sense of authentic learning [Braund and Reiss, 2006], participation as learning [Lave and Wenger, 1991], and a successful public engagement experience [Roger and Klistorner, 2016]. However, these differences in participation should be taken into account when evaluating the scientific, engagement or learning outcomes of BioBlitzes and field-based CS programs in general, depending on the goals that the program organizers have for the events. If the primary goal is for youth to engage with nature, science practices and learning activities such as Exploring, Observing and Identifying wildlife, then whether or not youth engage in the CS process by Recording does not matter as much. When aiming for participants to gain awareness and understanding of the scientific process [Robinson et al., 2013], participation in the whole process of data collection should be desirable to enable youth to experience the full range of the science practices and methods within the authentic context [Braund and Reiss, 2006]. This would provide the opportunity for youth to take ownership of CS data, an important way for youth to develop data literacy [Harris et al., 2020]. BioBlitzes as CS activities offer a range of opportunities for learning through participation in an authentic context [Lave and Wenger, 1991], so even unintentional restrictions on participation can be seen as restrictions on learning opportunities and identity development.

Our study is based on observational data only. We suggest further studies using additional instruments such as surveys or interviews, to investigate the youth perspective on their own participation, their awareness of potential additional activities within a BioBlitz context and their reflection on their contribution to scientific research. In addition, for further observational studies, we would suggest tracking whether young people engage in data submission after the observation interval or whether someone else records the youth biodiversity observations.

\section{Understanding participation profiles}

Our results add to the understanding of the experience element (output) of the logic model [Shirk et al., 2012] or respectively the use/participation element (activity) of MODEL-CS [Bruckermann et al., 2020]. We propose the three participation profiles as categories to systematically describe and compare BioBlitz participants' experience (Figure 3).

Our results clearly show that not all youth undergo the same BioBlitz experience, and while most youth experience several parts of the scientific process, only a few actually record data and experience the type of participation that distinguishes CS from education or engagement activities [Hecker et al., 2018]. We suggest the profiles could be easily applied to examine adult participants and other CS programs that focus on biodiversity data. 


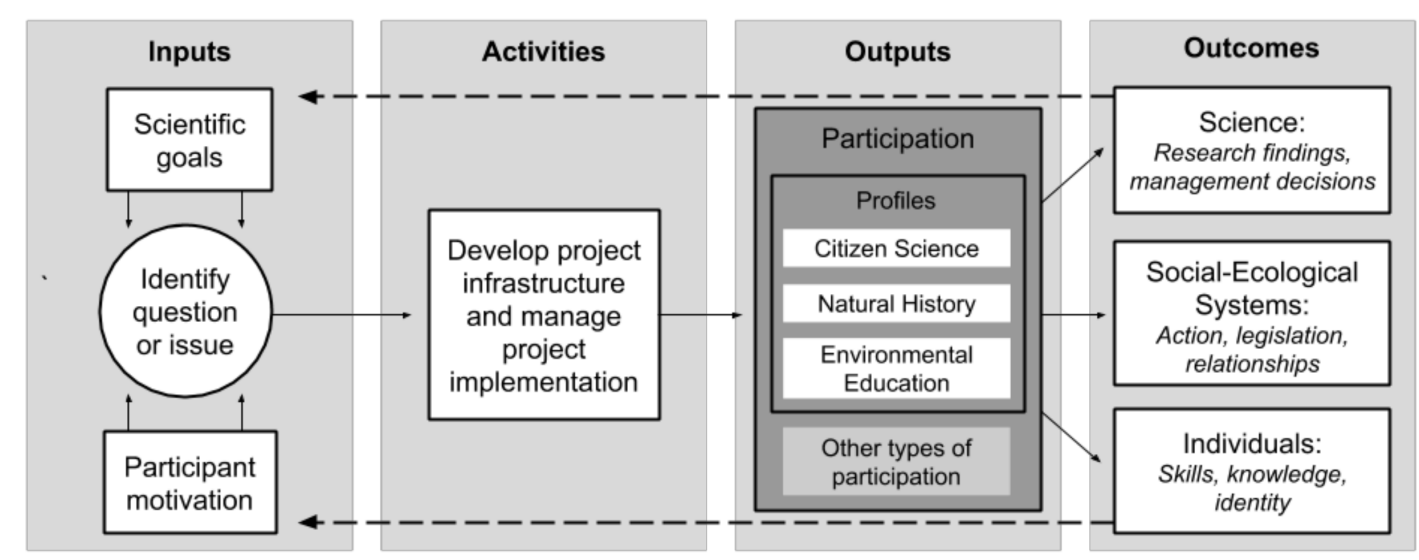

Figure 3. LEARN CitSci logic model (adapted from Shirk et al. [2012]).

The participation profiles may enable researchers and practitioners to better understand the participant experience during CS programs, and reflect on the extent to which actual participation patterns match the goals of the program. Further, they might be useful to examine participation across different settings and between different CS programs. Such analysis can inform the design of CS activities, to achieve the desired participation patterns and enhance outcomes both for science (by supporting more participants to submit data) and for participants. We suggest further research could investigate how the participation profiles relate to individual outcomes, leveraging our derived categories of participation and profiles. The developed participation profiles can act as a framework for a systematic analysis of factors that hinder or support participation and investigate the extent to which participation affects learning outcomes.

These findings help us better understand the nuances of how youth play a role in the collective effort to record and monitor biodiversity at local, national and global scales. Our results show that youth can and do participate in each of the five steps that could potentially contribute to the data collection of BioBlitzes as contributory CS projects, and that BioBlitzes provide valuable environmental and science engagement experiences for youth.

We found evidence that several youth, and even youth of elementary school-age, took part in the Recording step itself, which is the crucial step that actually provides data for research and land management. However, since the scientific goal of BioBlitzes is successfully recording biodiversity data points, we see this only rarely happens for youth. This highlights an opportunity for improved program design to address this shortcoming. Our results can be seen as an invitation for program organizers to reflect on their goals for youth participation in CS, and consider that there are many ways youth can participate in the authentic scientific process, but that by not Recording, many youth miss out on the crucial step in that process. We suggest that to engage more youth in the whole CS process at a BioBlitz, program designers need to better support youth to Record their observations, enabling them to contribute scientific data to the CS project. 
Acknowledgments This material is based upon work supported under a collaboration between the National Science Foundation (NSF), Wellcome, and the Economic and Social Research Council (ESRC) via a grant from the NSF (NSF grant no. 1647276) and a grant from Wellcome with ESRC (Wellcome grant no. 206202/Z/17/Z).

Disclaimer: any opinions, findings and conclusions or recommendations expressed in this material are those of the author(s) and do not necessarily reflect the view of NSF, Wellcome, or ESRC.

We would like to thank all the participating youth and their families, and the NHM staff and partners who helped with this study, especially Stephanie Holt. We thank Dr. Déana Scipio and Dr. Angela Calabrese Barton for their contributions to this research.

\section{References}

Aristeidou, M., Herodotou, C., Ballard, H. L., Young, A. N., Miller, A. E., Higgins, L. and Johnson, R. F. (2021). 'Exploring the participation of young citizen scientists in scientific research: the case of iNaturalist'. PLoS ONE 16 (1), e0245682. https://doi.org/10.1371/journal.pone. 0245682.

Baker, G. M., Duncan, N., Gostomski, T., Horner, M. A. and Manski, D. (2014). 'The BioBlitz: good science, good outreach, good fun'. Park Science 31 (1), pp. 39-45, 69.

Ballard, H. L., Robinson, L. D., Young, A. N., Pauly, G. B., Higgins, L. M., Johnson, R. F. and Tweddle, J. C. (2017). 'Contributions to conservation outcomes by natural history museum-led citizen science: examining evidence and next steps'. Biological Conservation 208, pp. 87-97. https://doi.org/10.1016/j.biocon.2016.08.040.

Bonney, R., Cooper, C. B., Dickinson, J., Kelling, S., Phillips, T., Rosenberg, K. V. and Shirk, J. (2009). 'Citizen science: a developing tool for expanding science knowledge and scientific literacy'. BioScience 59 (11), pp. 977-984. https://doi.org/10.1525/bio.2009.59.11.9.

Braund, M. and Reiss, M. (2006). 'Towards a more authentic science curriculum: the contribution of out-of-school learning'. International Journal of Science Education 28 (12), pp. 1373-1388. https://doi.org/10.1080/09500690500498419.

Bruckermann, T., Lorke, J., Rafolt, S., Scheuch, M., Aristeidou, M., Ballard, H., Bardy-Durchhalter, M., Carli, E., Herodotou, C., Kelemen-Finan, J., Robinson, L., Swanson, R., Winter, S. and Kapelari, S. (2020). 'Learning opportunities and outcomes in citizen science: a heuristic model for design and evaluation'. In: Electronic proceedings of the ESERA 2019 Conference. The beauty and pleasure of understanding: engaging with contemporary challenges through science education. Ed. by O. Levrini and G. Tasquier. Bologna, Italy: University of Bologna, pp. 889-898. URL: https://www . esera.org/publications/esera-con ference-proceedings/esera-2019.

Creswell, J. W. (2014). Research design: qualitative, quantitative, and mixed methods approach. 4th ed. Thousand Oaks, CA, U.S.A.: SAGE Publications.

da Silva, P. G. (2018). 'A unique BioBlitz at Point Reyes National Seashore, Marin County, California, U.S.A.' The Pan-Pacific Entomologist 94 (1), pp. 22-26. https://doi.org/10.3956/2018-94.1.22.

DITOs Consortium (2019). Developing a common evaluation tool for public engagement with biological recording events using the case study of City Nature Challenge 2018 in Europe. DITOs policy brief 13.

Emerson, R. M., Fretz, R. I. and Shaw, L. L. (1995). Writing ethnographic fieldnotes. Chicago, IL, U.S.A.: University of Chicago Press. https://doi.org/10.7208/chicago/9780226206851.001.0001. 
Golumbic, Y. N., Baram-Tsabari, A. and Fishbain, B. (2020). 'Engagement styles in an environmental citizen science project'. JCOM 19 (06), A03. https://doi.org/10.22323/2.19060203.

Gormally, C., Brickman, P., Hallar, B. and Armstrong, N. (2009). 'Effects of inquiry-based learning on students' science literacy skills and confidence'. International Journal for the Scholarship of Teaching and Learning 3 (2), 16. https://doi.org/10.20429/ijsotl.2009.030216.

Haklay, M. (2013). 'Citizen science and volunteered geographic information: overview and typology of participation'. In: Crowdsourcing geographic knowledge: volunteered geographic information (VGI) in theory and practice. Ed. by D. Sui, S. Elwood and M. Goodchild. Dordrecht, The Netherlands: Springer, pp. 105-122. https://doi .org/10.1007/978-94-007-4587-2_7.

Haklay, M., Fraisl, D., Greshake Tzovaras, B., Hecker, S., Gold, M., Hager, G., Ceccaroni, L., Kieslinger, B., Wehn, U., Woods, S., Nold, C., Balazs, B., Mazzonetto, M., Rüfenacht, S., Shanley, L., Wagenknecht, K., Motion, A., Sforzi, A., Riemenschneider, D., Dörler, D., Heigl, F., Schäfer, T., Lindner, A., Weißpflug, M., Mačiuliene, M. and Vohland, K. (2020). ‘Contours of citizen science: a vignette study'. SocArXiv. https://doi.org/10.31235/osf.io/6u2ky.

Harris, E. M., Dixon, C. G. H., Bridges Bird, E. and Ballard, H. L. (2020). 'For science and self: youth interactions with data in community and citizen science'. Journal of the Learning Sciences 29 (2), pp. 224-263. https://doi.org/10.1080/10508406.2019.1693379.

Hartry, A., Collins, M., Pande, A., Nava, R. and Waller, K. (2017). Evaluation of 2016 National Park BioBlitzes. A report submitted to The National Geographic Society by The Lawrence Hall of Science, University of California Berkeley. URL: https://www.informalscience.org/sites/default/files/Evaluation $\% 20$ of $\% 202016 \% 20$ National $\% 20$ Park $\% 20 B i o B l i t z e s$.pdf.

Hecker, S., Haklay, M., Bowser, A., Makuch, Z., Vogel, J. and Bonn, A. (2018). 'Innovation in open science, society and policy - setting the agenda for citizen science'. In: Citizen science. Innovation in open science, society and policy. Ed. by S. Hecker, M. Haklay, A. Bowser, Z. Makuch, J. Vogel and A. Bonn. London, U.K.: UCL Press, pp. 1-23. https://doi.org/10.14324/111.9781787352339.

Herodotou, C., Aristeidou, M., Miller, G., Ballard, H. and Robinson, L. (2020). 'What do we know about young volunteers? An exploratory study of participation in Zooniverse'. Citizen Science: Theory and Practice 5 (1), 2. https://doi.org/10.5334/cstp. 248.

Isaac, N. J. B. and Pocock, M. J. O. (2015). 'Bias and information in biological records'. Biological Journal of the Linnean Society 115 (3), pp. 522-531. https://doi.org/10.1111/bij.12532.

Lave, J. and Wenger, E. (1991). Situated learning: legitimate peripheral participation. Cambridge, U.K.: Cambridge University Press.

Leong, K. M. and Kyle, G. T. (2014). 'Engaging park stewards through biodiversity discovery: social outcomes of participation in BioBlitzes'. Park Science 31 (1), pp. 106-111.

Lewenstein, B. V. and Brossard, D. (2009). 'A critical appraisal of models of public understanding of science: using practice to inform theory'. In: Communicating science. New agendas in communication. Ed. by L. Kahlor and P. Stout. New York, NY, U.S.A.: Routledge, pp. 11-39. https://doi.org/10.4324/9780203867631. 
Miller-Rushing, A., Primack, R. and Bonney, R. (2012). 'The history of public participation in ecological research'. Frontiers in Ecology and the Environment 10 (6), pp. 285-290. https://doi.org/10.1890/110278.

Pellegrini, A. D., Symons, F. J. and Hoch, J. (2004). Observing children in the natural worlds: a methodological primer. 2nd ed. Mahwah, NJ, U.S.A.: Lawrence Erlbaum Associates.

Phillips, T. B., Ballard, H. L., Lewenstein, B. V. and Bonney, R. (2019). ‘Engagement in science through citizen science: moving beyond data collection'. Science Education 103 (3), pp. 665-690. https://doi.org/10.1002/sce.21501.

Pocock, M. J. O., Roy, H. E., Preston, C. D. and Roy, D. B. (2015). ‘The biological records centre: a pioneer of citizen science'. Biological Journal of the Linnean Society 115 (3), pp. 475-493. https://doi .org/10.1111/bij.12548.

Postles, M. and Bartlett, M. (2018). 'The rise of BioBlitz: evaluating a popular event format for public engagement and wildlife recording in the United Kingdom'. Applied Environmental Education E Communication 17 (4), pp. 365-379. https://doi.org/10.1080/1533015X.2018.1427010.

Robinson, L. D., Tweddle, J. C., Postles, M. C., West, S. E. and Sewell, J. (2013). Guide to running a BioBlitz. Natural History Museum, Bristol Natural History Consortium, Stockholm Environment Institute York and Marine Biological Association. URL: http://www. bnhc.org.uk/communicate/guide-to-runninga-bioblitz-2-0/.

Roger, E. and Klistorner, S. (2016). ‘BioBlitzes help science communicators engage local communities in environmental research'. JCOM 15 (03), A06. https://doi.org/10.22323/2.15030206.

Saldaña, J. (2009). The coding manual for qualitative researchers. London, U.K.: SAGE Publications.

Shirk, J. L., Ballard, H. L., Wilderman, C. C., Phillips, T., Wiggins, A., Jordan, R., McCallie, E., Minarchek, M., Lewenstein, B. V., Krasny, M. E. and Bonney, R. (2012). 'Public participation in scientific research: a framework for deliberate design'. Ecology and Society 17 (2), 29. https://doi.org/10.5751/ES-04705-170229.

Sobel, D. (1995). 'Beyond ecophobia: reclaiming the heart in nature education'. Clearing 91, pp. 16-20.

Tewksbury, J. J., Anderson, J. G. T., Bakker, J. D., Billo, T. J., Dunwiddie, P. W., Groom, M. J., Hampton, S. E., Herman, S. G., Levey, D. J., Machnicki, N. J., del Rio, C. M., Power, M. E., Rowell, K., Salomon, A. K., Stacey, L., Trombulak, S. C. and Wheeler, T. A. (2014). 'Natural history's place in science and society'. BioScience 64 (4), pp. 300-310. https://doi.org/10.1093/biosci/biu032.

United Nations (1992). Convention on biological diversity. URL: https://www.cbd.int/doc/legal/cbd-en.pdf.

West, S., Pateman, R. and Dyke, A. (2016). Data submission in citizen science projects. Report for Defra (project number PH0475). URL: https: //www . york. ac . uk/media /sei/documents/publications/projectreports/West-Pateman-Dyke-DEFRAData-Submission-in-Citizen-Science-Projects.pdf.

Authors

Julia Lorke is a Fellow at IPN — Leibniz Institute for Science and Mathematics Education and was a postdoctoral researcher at the Natural History Museum London. Julia is a qualified science teacher, worked as a science communication lecturer, in outreach and radio journalism. Her research focuses on informal learning, audience engagement and participation in science. She earned an MEd in Chemistry and Biology and a Ph.D. in Chemistry from Ruhr-University Bochum 
(Germany) as well as an MSc in Science Communication from Imperial College London. E-mail: lorke@leibniz-ipn.de.

Heidi Ballard is Professor of Environmental Science Education, and the Founder and Faculty Director of the Center for Community and Citizen Science at University of California, Davis. She conducts research focused on science and environmental learning that link communities, scientists, and environmental action. She was a high school biology teacher, and earned her MA in Science Education from Stanford University, before earning her Ph.D. in Environmental Science, Policy and Management from University of California-Berkeley.

E-mail: hballard@ucdavis.edu.

Annie Miller is the LEARN CitSci Project Coordinator at the California Academy of Sciences. During her undergraduate studies at Tufts University, she received a dual degree in Biology and Environmental Science. Her research interests include effects of human development on biodiversity and habitat degradation, but her passion is in science communication and outreach. Her previous work includes studying the genetic movement of an endangered Hawaiian waterbird and working with the San Francisco Recreation and Parks Department as an Environmental Educator. E-mail: aemiller235@gmail.com.

Rebecca Swanson is a post-doctoral scholar at Tufts University with the Center for Engineering Education and Outreach. Her research focuses on professional development of K-12 and informal STEM educators, including the design and implementation of interest-driven learning experiences. Rebecca is a credentialed $\mathrm{K}-12$ science teacher and former informal science educator, with a B.A. in Molecular, Cellular, and Developmental Biology from University of California Santa Cruz, and a Ph.D. in Curriculum and Instruction, Science Education from University of Colorado Boulder. E-mail: rebecca.swanson@tufts.edu.

Sasha Pratt-Taweh is the LEARN CitSci Project Coordination Officer at the Natural History Museum in London. She has worked in the museum learning sector for 9 years, as an educator and presenter at NHM and The Science Museum. Sasha's main professional interests are in biodiversity conservation and equal access to STEM education for underrepresented and ethnic minority groups. Sasha earned an MSc in Ecology, Evolution \& Conservation from Imperial College London and a BSc in Zoology from University College London. E-mail: sashalvp@gmail.com.

Jessie Jennewein is the LEARN CitSci Project Coordinator at the Natural History Museum of Los Angeles County. Since 2009, she has been working within the museum, from Education outreach to her current position with Community Science. Jessie received her undergraduate degree in Anthropology, focusing on visual ethnographic work. Currently, she's working on a Masters in Conservation Biology. Her graduate research looks at social media use in conservation and environmental justice, aligning with her passion of science advocacy and environmental activism. E-mail: jjennewe@nhm.org.

Lila Higgins is the Senior Manager of Community Science at the Natural History Museum of Los Angeles County (NHMLA) and a Co-PI for the LEARN CitSci project. Her work focuses on connecting people to nature, particularly in cities. She does this through many modes including community science, and is the 
co-founder of the City Nature Challenge. Lila holds a BS in Entomology from University of California, Riverside and an MA in Environmental Education from California State University, San Bernardino. E-mail: lhiggins@nhm.org.

Rebecca Johnson co-directs Citizen Science at the California Academy of Sciences, where she is also a Research Associate in the Department of Invertebrate Zoology. She develops programs and builds coalitions focused on people exploring their local nature and gathering biodiversity data for conservation. Rebecca earned a Ph.D. from the University of California, Santa Cruz in Ecology and Evolutionary Biology for her work using natural history museum collections and molecular phylogenetics to explore biogeography and color pattern evolution in nudibranchs. E-mail: rjohnson@calacademy.org.

Alison Young is the Co-Director of Citizen Science at the California Academy of Sciences, where she works to build community around nature connection and biodiversity documentation. Alison is co-lead of the annual City Nature Challenge, and she sits on the Board of Directors for the Citizen Science Association. Alison's background is in marine biology, she earned an M.A. in Biology from Humboldt State University for research focused on the potential effects of climate change on California's rocky intertidal communities. E-mail: ayoung@calacademy.org.

Maryam Ghadiri Khanaposhtani is a post-doctoral researcher at the Center for Community and Citizen Science at University of California, Davis. Her research focus is on investigating youth learning in natural history museum-led citizen science programs. Maryam's B.A. is in environmental science, her M.A. is in conservation biology, both from Tehran University, Iran and a Ph.D. in on soundscape ecology and free-choice STEM learning from Purdue University, U.S.A. E-mail: mghadiri@ucdavis.edu.

Lucy Robinson is Citizen Science Manager at the Natural History Museum London, and Principal Investigator for the LEARN CitSci partnership. She has been a practitioner in citizen science for over ten years, and has co-authored the Guide to Citizen Science (2012), Guide to Running a BioBlitz (2013) and Ten Principles of Citizen Science (2015). She recently served as Vice Chair of the European Citizen Science Association (ECSA). Lucy holds a BSc Zoology and an MSc Biodiversity and Conservation. E-mail: 1.robinson@nhm.ac.uk.

\section{How to cite}

\section{Supplementary material}

Lorke, J., Ballard, H. L., Miller, A. E., Swanson, R. D., Pratt-Taweh, S., Jennewein, J. N., Higgins, L., Johnson, R. F., Young, A. N., Ghadiri Khanaposhtani, M. and Robinson, L. D. (2021). 'Step by step towards citizen science - deconstructing youth participation in BioBlitzes'. JCOM 20 (04), A03. https:/ / doi.org/10.22323/2.20040203.

Available at https:/ / doi.org/10.22323/2.20040203.

Supplementary material A: Additional Information on BioBlitzes

Supplementary material B: Research Methods Details

(C) The Author(s). This article is licensed under the terms of the Creative Commons Attribution - NonCommercial — NoDerivativeWorks 4.0 License. ISSN 1824-2049. Published by SISSA Medialab. jcom.sissa.it 